\title{
Implementasi Metode Waterfall Pada Sistem Informasi Sentra Pelayanan Kepolisian Terpadu(SPKT) Polsek Karawang Kota
}

\author{
Muhamad Tabrani ${ }^{1}$, Karin Lapelia ${ }^{2}$ \\ Email: muhammad.mtb@bsi.ac.id, karinrapelia55@gmail.com \\ Universitas Bina Sarana Informatika PSDKU Karawang
}

\begin{abstract}
Abstrak
Kantor Polsek Karawang Kota merupakan lembaga kepolisian yang melayani masyarakat khususnya di dua wilayah kecamatan yaitu Kecamatan Karawang Barat dan Kecamatan Karawang Timur. Bidang Sentra Pelayanan Kepolisian Terpadu (SPKT) memiliki fungsi diantaranya melayani pengaduan masyarakat yang terkena tindak kriminalitas. Selama ini dalam pelaksanaan kegiatan pelayanan pada unit SPKT masih menggunakan sistem konvensional dan belum terkomputerisasi. Dengan demikian sering kali dijumpai terjadi kesalahan dalam pencatatan, kurang akuratnya laporan yang dibuat, serta lambatnya dalam pencarian data yang diperlukan dan kurangnya informasi kepada masyarakat tentang persyaratan permohonan SSTLP (Surat Tanda Terima Lapor Polisi). Untuk itu perlu dibangun sistem informasi SPKT berbasis komputer di kantor Polsek Karawang Kota yang dapat memudahkan petugas kepolisian dalam proses pembuatan, hingga pengarsipan STTLP. Metode yang digunakan yaitu menggunakan metode waterfall dengan menggunakan alat bantu pengembangan sistem berupa UML, ERD dan LRS. Perancangan sistem ini merupakan solusi yang baik untuk memecahkan permasalahan yang ada pada unit SPKT Polsek Karawang Kota, serta dengan sistem yang terkomputerisasi dapat tercapai suatu kegiatan yang efektif dan efisien dalam menunjang pelayanan pada masyarakat dan perkerjaan pada instansi.
\end{abstract}

Kata kunci : Sistem Informasi, Pelayanan kepolosian, Waterfall

\section{Pendahuluan}

Polsek Karawang Kota adalah sebuah kantor polisi yang melayani masyarakat di Kota Karawang, Jawa Barat. Polsek tersebut memiliki cakupan wilayah di 2 kecamatan yaitu kecamatan Karawang Barat dan Karawang Timur. Tidak berbeda dengan kantor polisi lain di Indonesia, Polsek Karawang Kota inilah tempat para polisi melakukan koordinasi sebelum turun ke lapangan, mengurus administrasi internal kepolisian, dan tentunya melakukan pelayanan kepada masyarakat setempat. Kepolisian bidang SPKT (Sentra Pelayanan Kepolisisan Terpadu) mempunyai fungsi diantaranya melayani pengaduan masyarakat yang terkena tindak kriminalitas yaitu seperti laporan pencurian, kehilangan barang berharga, penipuan, penggelapan, perampokan dan sebagainya.

Pada Polsek Karawang Kota jika masyarakat melakukan pengaduan ataupun permohonan kepada kepolisian unit SPKT (Sentra Pelayanan Kepolisian Terpadu), petugas masih menggunakan sistem konvensional dan belum terkomputerisasi dimana kekurangan dari sistem ini adalah memungkinkan terjadi kesalahan dalam pencatatan, kurang akuratnya laporan yang dibuat, keterlambatan dalam pencarian data yang diperlukan STTLP (Surat Tanda Terima Laporan Polisi) maka petugas harus menulis ulang pada buku untuk pengarsipan, kemudian jika masyarakat melakukan permohonan untuk kedua kalinya petugas harus menulis ulang data pemohon karena membutuhkan waktu lama untuk pencarian data. Dan juga Kepala Administrasi SPKT masih mendapatkan laporan secara manual, sehingga pengawasan terhadap SPKT kurang efektif.

Melihat banyaknya keluhan masyarakat saat ini tentunya masyarakat membutuhkan pelayanan yang cepat di bagian SPKT. Karena SPKT merupakan pusat pelayanan kepolisian dalam melayani masyarakat, untuk peningkatan dan memudahkan pelayanan maka diperlukan perangkat lunak yang lebih akurat. Apabila sistem sudah terkomputerisasi, maka petugas bisa melakukan tugasnya lebih cepat agar tidak memakan waktu lama serta tidak menimbulkan antrian masyarakat yang terlalu banyak dan pengarsipan pun akan lebih efektif. Dan pengawasan oleh Kepala Admistrasi SPKT dapat secara langsung dilakukan dengan melihat laporan yang telah tersedia pada sistem. Atas dasar identifikasi masalah yang telah dipaparkan diatas, maka rumusan masalah pada penelitian ini adalah bagaimana 
membuat program untuk Sistem Pelayanan Kepolisisan Terpadu pada Polsek Karawang Kota guna meningkatkan pelayanan terhadap masyarakat.

\section{Metode Penelitian}

Menurut Kadir dalam (Dewi, 2018) mengemukakan bahwa "Sistem informasi adalah sebuah rangkaian prosedur formal dimana data dikelompokkan, diproses menjadi informasi, dan didistribusikan kepada pemakai".

Sedangkan, menurut Sutarbi (2016:40) mendefinisikan bahwa: Sistem Informasi adalah suatu sistem di dalam suatu organisasi yang mempertemukan kebutuhan pengolahan transaksi harian yang mendukung fungsi operasional yang bersifat manajerial dengan kegiatan strategi dari suatu organisasi untuk dapat menyediakan kepada pihak luar tertentu dengan laporan-laporan yang diperlukan.

Menurut Mayangky dan Suharyanto (2018: 67) menjelaskan bahwa "Pelayanan adalah kegiatan yang dilakukan seseorang atau sekelompok orang dengan faktor materil melalui sistem, prosedur dan metode tertentu dalam rangka usaha memenuhi kepentingan orang lain sesuai haknya.

Menurut Mayangky dan Suharyanto (2018: 68) mengemukakan bahwa "Tugas dari SPKT adalah Memberikan pelayanan Kepolisian secara terpadu kepada masyarakat dalam bentuk penerimaan dan penanganan laporan atau pengaduan, pemberian bantuan atau pertolongan dan pelayanan surat keterangan dan menyajikan informasi yang berkaitan dengan kepentingan tugas kepolisian guna jdapat diakses sesuai dengan ketentuan peraturan perundang-undangan.

Menurut Rosa dan Shalahuddin bahwa (2018: 43), "Basis Data adalah sistem terkomputerisasi yang tujuan utamanya adalah memelihara data yang sudah diolah atau informasi dan membuat informasi tersedia saat dibutuhkan".

Menurut Rismayanti (2014: 36) mengemukakan bahwa "Netbeans merupakan salah satu IDE yang dikembangkan dengan bahasa pemograman java. Netbeans mempunyai lingkup pemograman java terintegrasi dalam suatu perangkat lunak yang didalamnya menyediakan pembangunan GUI, text editor, complier, dan interpreter".
Menurut Rosa dan Shalahuddin (2018: 50), bahwa "Entity Relationship Diagram atau (ERD) digunakan untuk pemodelan basis data relasional sehingga jika penyimpanan basis data menggunakan OODBMS, maka perancangan basis data tidak perlu menggunakan ERD”.

Menurut Kristanto, A. dalam Nissa dan Suharyanto (2018:69), "Logical Record Structured (LRS) adalah representasi dari struktur record-record pada tabel-tabel yang terbentuk dari hasil relasi antar himpunan entitas. Menentukan kardinalitas, jumlah tabel, dan Foreign Key".

\section{Hasil dan Pembahasan}

\section{A. Prosedur Sistem Berjalan}

Berikut ini adalah prosedur sistem berjalan unit SPKT pada Polsek Karawang Kota meliputi beberapa proses antara lain sebagai berikut:

1. Prosedur Pendataan Persyaratan Pemohon datang dengan membawa persyaratan sesuai kebutuhan lalu mengisi buku registrasi, kemudian pemohon antri untuk melakukan proses pengaduan dan memberikan persyaratan sesuai dengan jenis laporan Surat Tanda Terima Laporan Polisi (STTLP) kepada petugas kepolisian, yang meliputi STTLP yaitu:

a) Laporan Polisi (LP)

Persyaratan: Memberikan keterangan dan barang bukti.

b) Surat Keterangan Tanda Lapor Kehilangan (SKTLK)

Persyaratan kehilangan dokumen: Membawa fotokopi dokumen hilang atau memberikan nomor induk dokumen yang hilang.

Persyaratan kehilangan kendaraan: Membawa dokumen kendaraan.

c) Surat Tanda Terima Pemberitahuan (STTP)

Persyaratan: Membawa surat permohonan dan melampirkan jadwal acara, susunan panitia, nama peserta/undangan, nama pembicara, $\mathrm{ad} / \mathrm{rt} /$ organisasi, foto copy ktp penanggung jawab, akte pendirian organisasi dan proposal.

2. Prosedur Analisa Pengaduan

Petugas kepolisian menerima persyaratan dan pengaduan masyarakat, 
lalu menganalisa laporan dengan keterangan dan barang bukti yang selanjutnya dibuatkan rekomendasi pengaduan sesuai jenis STTLP.

\section{Prosedur Laporan SPKT}

Petugas Kepolisian Urusan Administrasi (URMIN) menerima data pengaduan dan lalu membuat Surat Tanda Terima laporan Polisi (STTLP) sesuai dengan jenis pengaduan kemudian diberikan kepada masyarakat/ pemohon. Kemudian petugas mencatat laporan yang masuk dalam buku register dan melaporkan kepada Kepala Administrasi (KA) SPKT secara berkala.

B. Perancangan Sistem Informasi

1. Kebutuhan Pengguna

Pada aplikasi sentra pelayanan kepolisian terpadu memiliki dua pengguna yang dapat saling berinteraksi dalam lingkungan sistem, yaitu : Petugas SPKT dan Kepala Administrasi. Kedua pengguna tersebut memiliki karakteristik interaksi dengan sistem yang berbedabeda dan memiliki kebutuhan informasi yang berbeda-beda, sebagai berikut:

a. Skenario Kebutuhan Petugas SPKT

1) Melakukan Login

2) Mengelola Menu Utama

3) Mengelola Data Petugas

4) Mengelola Data Pemohon

5) Mengelola Data Pengaduan

6) Mencetak Data Laporan Bulanan

7) Melakukan Logout

b. Skenario Kebutuhan KA SPKT
1) Melakukan Login
2) Mengelola Menu Utama
3) Mencetak Data Laporan Bulanan
4) Melakukan Logout

2. Kebutuhan Sistem

a. Pengguna harus melakukan login terlebih dahulu untuk dapat mengakses aplikasi dengan menginput username dan password agar privasi dari pengguna masingmasing dapat terjaga keamanannya.

b. Pengguna harus melakukan logout setelah selesai menggunakan aplikasi.

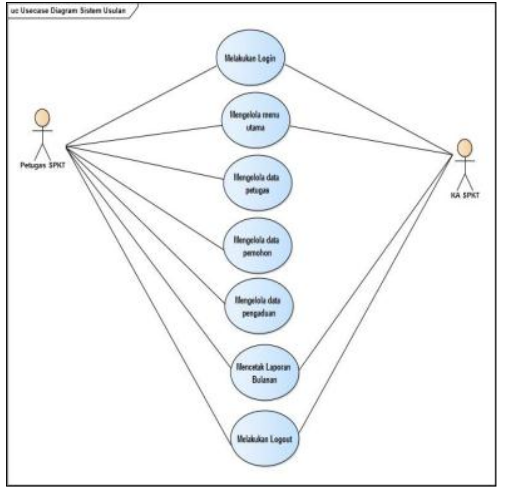

Gambar 1. Diagram Use Case Sistem Informasi

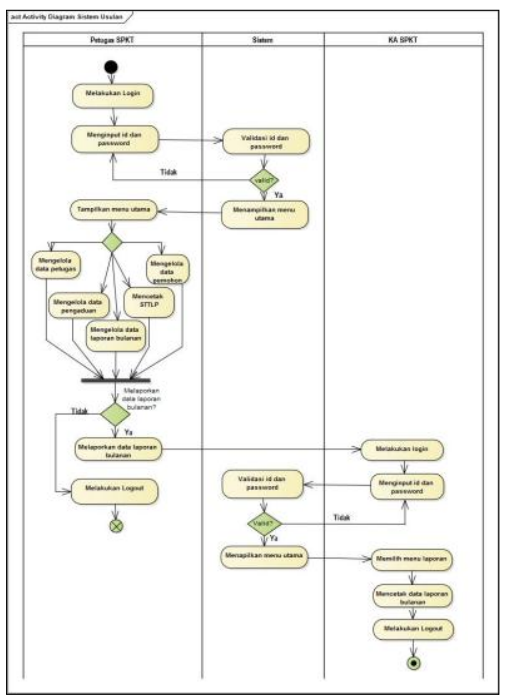

Gambar 2. Activity Diagram Sistem

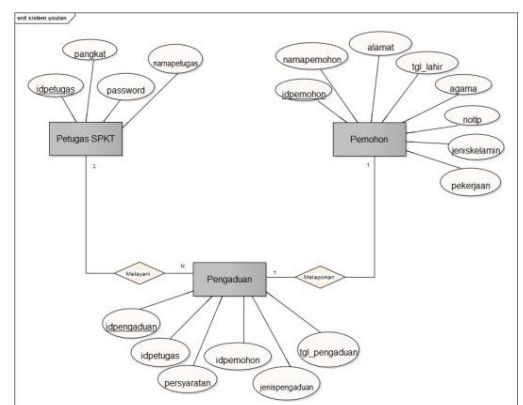

Gambar 3. ERD Sistem Informasi

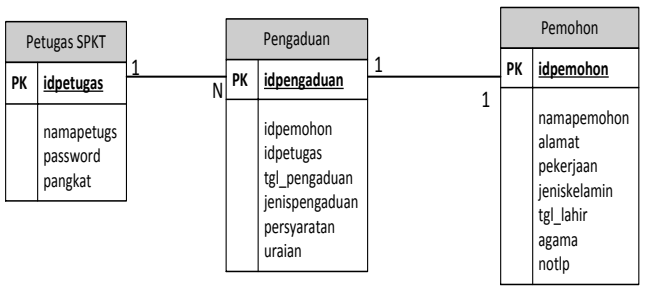

Gambar 4. LRS Sistem 


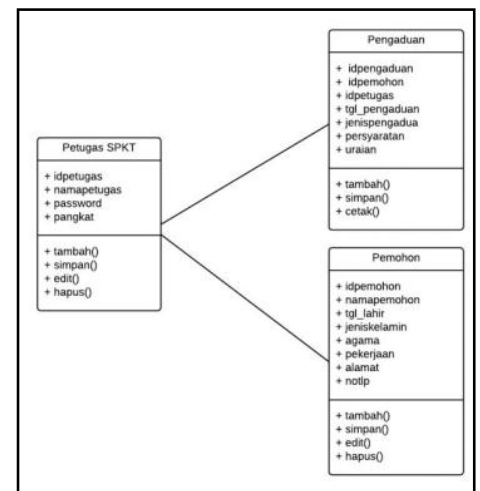

Gambar 5. Class Diagram Sistem

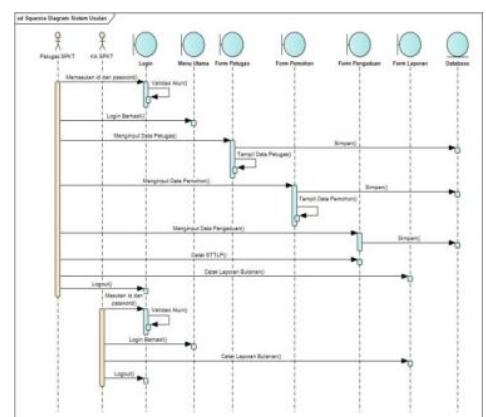

Gambar 6. Squence Diagram Sistem

C. Implementasi

1. Rancangan Tampilan Menu Login.

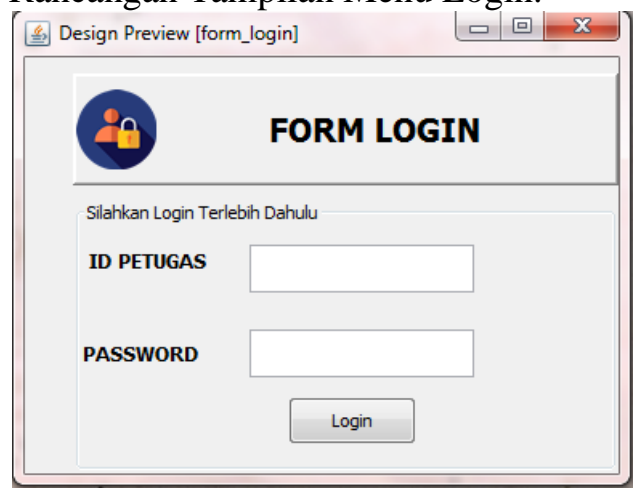

Gambar 7. Tampilan Menu Login

2. Rancangan Tampilan Menu Utama

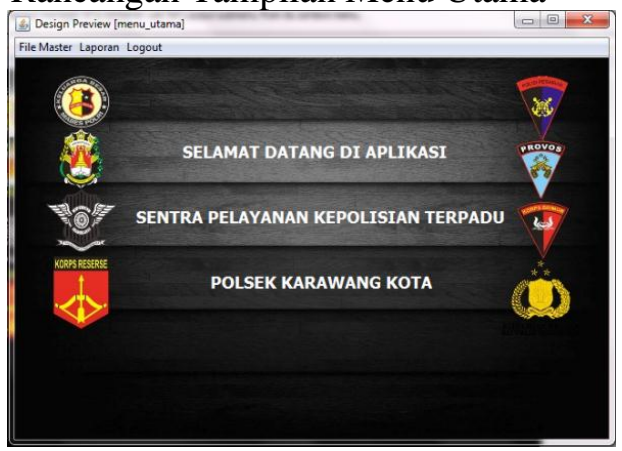

Gambar 8. Tampilan Menu Utama
3. Rancangan Tampilan Menu Data Petugas

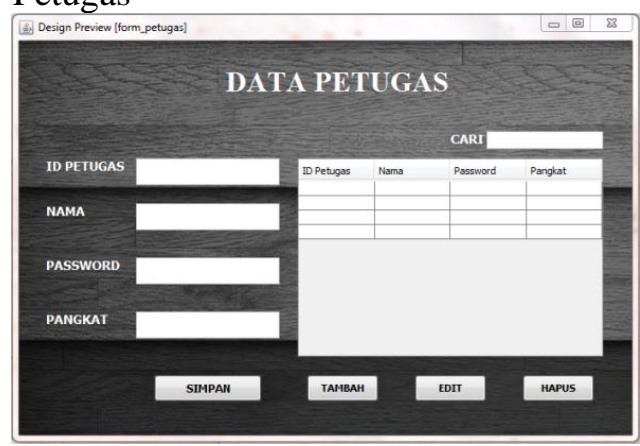

Gambar 9. Tampilan Menu Data Petugas

4. Rancangan Tampilan Menu Data Pemohon

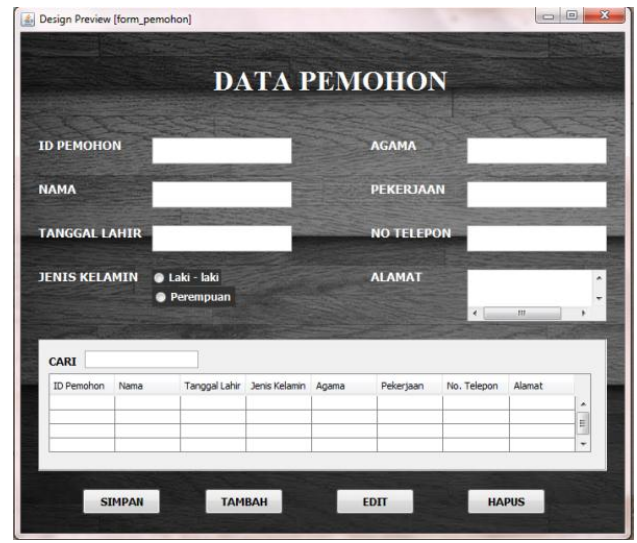

Gambar 10. Tampilan Menu Data Pemohon

5. Rancangan Tampilan Menu Data Pengaduan

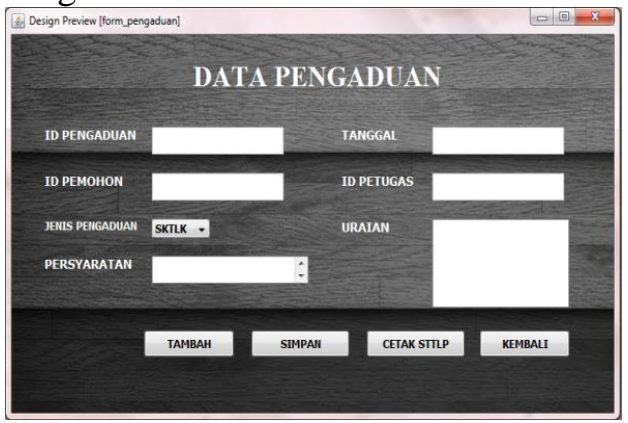

Gambar 11. Tampilan Menu Data Pengaduan 
6. Rancangan Tampilan Menu Laporan Bulanan

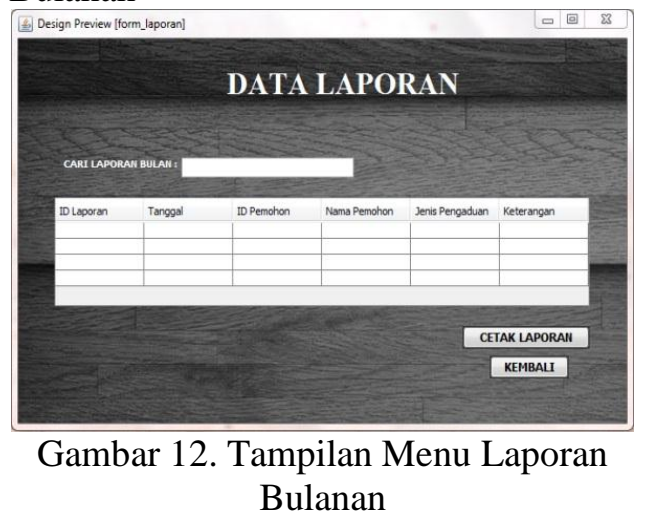

\section{Kesimpulan}

Berdasarkan kegiatan yang dilakukan penulis mulai dari tahapan proses observasi sampai tahap perancangan sistem, maka penulis dapat mengambil kesimpulan adalah sebagai berikut:

1. Kepolisian masih menggunakan sistem konvensional belum terkomputerisasi sehingga memungkinkan pada saat proses berlangsung terjadi kesalahan dalam pencatatan, kurang akuratnya laporan yang dibuat, keterlambatan dalam pencarian data yang diperlukan untuk pengolahan data permohonan STTLP (Surat Tanda Terima Laporan Polisi) menjadi kurang efektif.

2. Pengembangan sistem dimulai dari pembuatan database dapat menghasilkan kualitas informasi yang lebih dari sistem sebelumnya.

3. Hasil dari pengembangan sistem, bahwa sistem pelayanan SPKT pada kantor Polsek Karawang Kota telah berhasil dirancang.

4. Sistem dapat digunakan oleh beberapa komputer sehingga dapat mempermudah pelayanan SPKT dan dapat diintregasikan dengan baik.

5. Dengan sistem ini pengawasan dapat secara langsung dilakukan oleh Kepala Administrasi SPKT dengan melihat laporan yang telah ada pada sistem yang terintegrasi, sehingga bisa di lihat kapanpun.

6. Sistem ini dapat menampilkan data petugas, data pemohon, data pengaduan, dan laporan bulanan yang dihasilkan dari pengaduan masyarakat setiap bulannya.

\section{Daftar Pustaka}

[1] Atik Rismayanti. (2014). Sistem Informasi Pengelolaan Keuangan Pada Desa Ngadirejan. Http://Ijns.Org/Journal/Index.Php/Speed/ Article/View/1321/1309

[2] Dewi, S. C. (2018). Perancangan Sistem Informasi Penerimaan Kas Pada PT. Andita Mas Bekasi. Https://Ejournal.Bsi.Ac.Id/Ejurnal/Index. Php/Paradigma/Article/View/3048/Pdf, $10,2$.

[3] Jogiyanto. (2014). Analisis \& Desian Sistem Informasi Pedekatan Terstruktur, Teori dan Praktik Aplikasi Bisnis (III; Andi, ed.). Yogyakarta: CV Andi Offset.

[4] Mardi. (2014). Sistem Informasi Akuntasi (Risman Sikumbang, ed.). Bogor: Ghalia Indonesia.

[5] Mayangky, N. A., \& Suharyanto, S. (2018). Perancangan Sistem Informasi Sentra Pelayanan Kepolisian Terpadu Pada Polsek Citeureup Cimahi. Jurnal Sisfokom (Sistem Informasi Dan Komputer), $\quad 7(1), \quad 67$. https://doi.org/10.32736/sisfokom.v7i1.29 $\underline{5}$

[6] Pratama, I. putu A. E. (2014). Sistem Informasi dan Implementasinya. Informatika, Bandung. https://doi.org/10.1051/00046361:20078778

[7] Priyadi, Y. (2014). Kolaborasi SQL dan ERD dalam Implementasi Database (Maya, ed.). Yogyakarta: Andi.

[8] Rakhman, A., \& Sabanise, A. Y. F. (2019). Sistem Informasi Stok Kebutuhan Darah Pada Palang Merah Indonesia Dengan Metode Weighted Moving Average. Syntax Literate; Jurnal Ilmiah Indonesia, 4(7), 24-32.

[9] Shalahuddin, R. A. Sukamto. dan M. (2018). Rekayasa Perangkat Lunak Terstruktur dan Berorientasi Objek (revisi). Bandung: Informatika Bandung.

[10] Sukamto, R. A. dan S. M. (2015). Rekayasa Perangkat Lunak Terstruktur dan Berorientasi Objek. Bandung: Informatika Bandung.

[11] Sutarbi, T. (2016). Sistem Informasi Manajemen (Th. Arie P, ed.). Yogyakarta: Andi. 